\title{
A CONTRIBUIÇÃO DE LOUIS LE FUR AO NEO-JUSNATURALISMO INTERNACIONALISTA: DO COMBATE TEÓRICO AO VOLUNTARISMO AO FUNDAMENTO DO DIREITO INTERNACIONAL
}

\author{
Leandro \\ Tripodi ${ }^{1}$ \\ Gustavo ${ }^{1.2}$ \\ Brígido \\ Bezerra \\ Cardoso
}

\section{Resumo}

A influência de Louis Le Fur é sintetizada pela retomada do pensamento jusnaturalista em meio a um contexto positivista de ideias e teorias jurídicas. Le Fur analisa a vida internacional dos Estados, dissertando sobre a soberania, seus fundamentos e limites; estuda as confederações de Estados e analisa criticamente a Sociedade das Nações à luz dos projetos iluministas de paz perpétua; por fim, assenta o fundamento do Direito Internacional no direito racional ou objetivo, como limitação à vontade dos Estados, orientando-se pela noção de finalidade - o bem comum da sociedade internacional -, apoiada na ponderação das razões morais (o bom) e econômicas (o útil), o que resultará numa síntese jurídica (o justo).

Palavras-chave: Neo-jusnaturalismo. Sociedade das Nações. Confederações de Estados.

\footnotetext{
${ }^{1}$ Doutor em Direito Internacional pela USP. Foi pesquisador visitante, em nível de doutorado, da Universidade de Viena e da Comissão das Nações Unidas para o Direito do Comércio Internacional (UNCITRAL). Idealizador e co-organizador do Concurso de Monografias "Professor Albert H. Kritzer" sobre a CISG. E-mal: tripodi@usp.br

1.2 Doutorando em Direito Constitucional pela Universidade de Fortaleza (UNIFOR). Mestre em Políticas Públicas e Sociedade pela Universidade Estadual do Ceará. Aluno especial no Programa de Pós-graduação em Direito da FD-USP. Especialista em Direito e Processo Administrativos pela Universidade de Fortaleza (UNIFOR). Bacharel em Direito pela Universidade Federal do Ceará.
} 


\section{INTRODUÇÃO}

Louis Erasme Le Fur (1870-1943), jurista francês, membro do Institut de Droit International, professor da Universidade de Paris e ministrante na Academia de Direito Internacional da $\mathrm{Haia}^{2}$, inovou na doutrina francesa com sua obra État Fédéral et Confédération d'Etats (1896), fruto de sua tese de doutorado, bem como trouxe importantes acréscimos ao pensamento internacionalista do século vinte, sob a vertente neo-jusnaturalista do Direito Internacional. Ensina Vignali que essa corrente, desenvolvida no período do entreguerras, representa uma resposta às insatisfações de certos autores $^{3}$ com o surgimento de doutrinas totalitárias e com as análises insuficientes em torno do problema do fundamento do Direito Internacional, procurando adotar uma pauta sustentada em valores universais e renovando o tronco de pensamento jusnaturalista 4 .

Este trabalho analisará a contribuição de Le Fur ao Direito Internacional em suas duas obras-mestras: primeiramente, a já citada État Fédéral et Confédération d'Etats (1); em segundo lugar, a obra Précis de Droit International Public (1933), produto de sua fase madura (2), em que formula sua abordagem acerca do fundamento do Direito Internacional. A análise das duas obras em sequência será importante a fim de mostrar a evolução de suas ideias, que culminaram com a formulação de uma teoria que pode ser denominada de neo-jusnaturalista.

Procuraremos ser fieis ao pensamento do autor, reservando comentários opinativos para a Conclusão, e deixando ao leitor a reflexão a respeito do aggiornamento das ideias discutidas e das posições adotadas por Le Fur.

CONSIDERAÇÕES DE LE FUR SOBRE O ESTADO, A SOBERANIA E AS CONFEDERAÇÕES DE ESTADOS, CONSUBSTANCIADAS EM ÉTAT FÉDÉRAL ET CONFÉDÉRATION D'ÉTATS

${ }^{2}$ LE FUR, Louis. Règles Générales du Droit de la Paix. Recueil des Cours de l'Académie de La Haye, Vol. 58, 1936.

${ }^{3}$ Dentre os quais não apenas Le Fur, mas Cavare, Salvioli, Brierly, Sauer, Van Maydte, Verdross, etc., incluindo Albuquerque Mello, no Brasil.

${ }^{4}$ VIGNALI, Heber Arbuet. El fundamento del derecho internacional publico. In: ARÉCHAGA, E.J. ; VIGNALI, H.A.; RIPOLL, R.P. Derecho Internacional Publico: Principios, normas y estructuras. Montevideo: Fundación de Cultura Universitaria, 2005, p. 96-97. 
Em État Fédéral et Confédération d'États, Le Fur reconhece que, em fins do século dezenove, o Estado unitário, tomado até então como o "Estado-tipo", tornava-se cada vez mais raro, e diversas manifestações passavam a ocupar espaço e se tornar importantes, tais como: os Estados compostos e os sistemas de Estados; as uniões reais e pessoais; os Estados federais; as confederações de Estados; os Estados protetores e protegidos; e os Estados possuidores de províncias ou colônias, dotadas de autonomia e auto-administração5.

As questões postas por Le Fur como dignas de análise diante da realidade acima delineada podem ser assim resumidas: 1) é a soberania uma qualidade essencial do Estado? 2) Seria a soberania indivisível a ponto de não poder pertencer, dentro do mesmo território, a mais de um ente político, com exclusão das "coletividades públicas" de ordem inferior? ${ }^{6}$ Para ele, a primeira delas parece estar pacificada no momento em que escreve. No tocante à segunda questão, entende Le Fur que há confusão entre soberania e self-government: não é necessário, acrescenta, que uma comunidade seja soberana para que possua autonomia e direito de auto-administração. ${ }^{7}$

A obra divide-se em duas partes: na primeira delas, o autor procede a uma abordagem histórica da formação do Estado federal na Antiguidade e na época moderna, a qual se subdivide, por sua vez, na análise dos Estados federais europeus (República das Províncias Unidas, Império Alemão e Confederação Suíça), dos Estados federais do Novo Mundo (Estados Unidos da América, México, Venezuela, Argentina e Brasil), do movimento federal na Inglaterra e em suas colônias (como Canadá e Austrália) e das vantagens e inconvenientes da forma federativa, assim como da relação entre federalismo e paz.

A segunda parte da obra é dedicada à construção de uma teoria jurídica do Estado federal e das confederações de Estados. Le Fur defende que a soberania é o único critério caracterizador da noção de Estado, rejeitando aqueles baseados na organização dos poderes públicos, na finalidade ou na aquisição de direitos exclusivos por parte do

\footnotetext{
${ }^{5}$ LE FUR, Louis. État Fédéral et Confédération d'États. Paris : Librairie Générale de Jurisprudence, 1896, p. I.

${ }^{6}$ Id., p. III.

7 Id., p. IV.
} 
Estado, por não permitirem, segundo o autor, estabelecer uma diferenciação entre o Estado não soberano e outras coletividades inferiores. ${ }^{8}$ No tocante ao fundamento da soberania, Le Fur critica a construção de autores como Jellinek, Rosin, Haenel e Borel, por entender que levam à conclusão de que a soberania concederia um poder absoluto e ilimitado ao Estado, "que não teria outra regra a seguir a não ser a sua própria vontade; ideia da qual decorre a própria negação do direito". ${ }^{9}$ Como se verá, Le Fur retornará a esta concepção e a intensificará, sendo ela importante para sua formulação do fundamento do Direito Internacional, de forma crítica em relação à teoria da autolimitação.

Negar a existência de restrições à soberania, prossegue Le Fur, corresponderia fatalmente a identificar soberania e onipotência; "a identificar, como bom e justo, aquilo que corresponde à vontade do Estado, é dizer, a vontade de um homem ou a de uma maioria ignorante e versátil”. ${ }^{\circ} \mathrm{O}$ Estado, porém, não cria o direito à sua fantasia; concebida como absoluta e ilimitada, a soberania nunca existiu senão que na mente de certos teóricos. ${ }^{11}$

Ao contrário, o Estado encontra, segundo Le Fur, tanto num princípio que lhe é superior, aquele do Direito, como na própria existência dos indivíduos e coletividades que o compõem, limites intransponíveis, tanto na prática quanto na teoria. Tais limites decorrem do Direito, assim considerado, ou também, como se costuma dizer, do direito natural ou racional. ${ }^{12}$ "O Estado, pelo único fato de constituir uma pessoa de direito internacional, possui, como toda pessoa livre, direitos e deveres." ${ }^{33}$ Não é a soberania, segundo Le Fur, que coloca o Estado acima do Direito; ela tem apenas o condão de lhe permitir constatar - e sancionar - o Direito de conformidade com a sua natureza, seja para o próprio Estado, seja para os indivíduos e para as coletividades a ele submetidos. ${ }^{14}$

Quanto à determinação das restrições à soberania, trata-se de uma questão segundo ele reservada à Filosofia do Direito; porém, as considerações que dizem

\footnotetext{
${ }^{8}$ Id., p. 395-ss.

9 Id., p. 433 (tradução nossa).

${ }^{10}$ Id., p. 434 (tradução nossa).

${ }^{11}$ Id., p. 437.

${ }^{12}$ Id., p. $437-438$.

${ }^{13}$ Id., p. 438 (tradução nossa).

${ }^{14}$ Id., p. 438-439.
} 
respeito à finalidade são essenciais para sua solução. ${ }^{15} \mathrm{~A}$ finalidade do Estado, segundo Le Fur, como "forma suprema de organização humana”, é a garantia da condição essencial de sua organização e dos esforços humanos coletivos, por meio do Direito. Mas essa finalidade, apesar de universal, não é exclusiva e ilimitada: encontra-se, na verdade, no livre desenvolvimento de suas partes constitutivas. ${ }^{16}$ Tal finalidade é universal unicamente na medida em que todos os fins humanos encontram-se com ela numa relação de dependência; em que todos encontram-se a ela subordinados em seu dever de contribuir em alguma medida para o progresso social; tendo por isso mesmo o Estado o direito de exigir que os indivíduos "se conformem a seu plano geral de ação, vez que seu fim coletivo supremo domina todos os fins particulares" ${ }^{17}$

A obra prossegue com a análise da natureza jurídica da soberania. Aqui, Le Fur trata especificamente das restrições voluntárias à soberania, a quais podem decorrer de tratados ou dos contratos firmados com coletividades não soberanas que o compõem, ou com particulares. Neste segundo caso, Le Fur tem em vista as restrições impostas pelo Direito interno, das quais resultam duas consequências importantes: 1) que o Estado será o único juiz de qualquer discórdia que possa surgir a partir de tal contrato e 2) que a coletividade não soberana em questão não poderá recorrer ao meio supremo do qual dispõe um Estado soberano para resolver suas diferenças: o direito da guerra. ${ }^{18}$ Veremos que Le Fur passará a ser crítico desta formulação a partir da obra Précis de Droit International Public.

O autor ainda analisará, com especificidade, o Estado federal e as confederações de Estados. Do ponto de vista do Direito Internacional, interessa particularmente sua análise da natureza jurídica da confederação de Estados e da situação destas no plano do Direito Internacional Público.

Nesse diapasão, entende Le Fur que as confederações de Estados, sem sombra de dúvida, não são soberanas, pois cada de um dos Estados constituintes mantém a sua soberania. ${ }^{19}$ Decorre essa consequência da máxima de que não podem conviver, no

\footnotetext{
15 Id., p. 439.

${ }^{16}$ Id., p. 439-440.

17 Id., ibid. (tradução nossa).

${ }^{18}$ Id., p. 454-455.

19 Id., p. 498.
} 
mesmo território, dois Estados soberanos; nesse sentido, "se os Estados confederados são soberanos, é assim impossível que o poder central o seja ao mesmo tempo que eles”. ${ }^{20}$ Qualquer modificação à constituição da confederação de Estados, por outro lado, deve ser aceita à unanimidade pelos Estados membros, sob pena de os dissidentes usarem do direito de secessão a fim de salvaguardarem sua própria soberania. ${ }^{21}$ Em suma, a confederação de Estados, para Le Fur, não passa de uma associação destes, repousando sobre uma base inteiramente contratual. ${ }^{22}$

No plano internacional, Le Fur reconhece a personalidade jurídica da confederação de Estados, assim como "das coletividades públicas não soberanas dotadas de certas atribuições internacionais", entre as quais enumera a Santa-Sé, a Liga Hanseática, o Zollverein alemão e outras. ${ }^{23}$ "E precisamente a existência da confederação de Estados", diz Le Fur, é que "constitui ela própria a prova mais evidente da existência em direito internacional de pessoas morais outras que os Estados". ${ }^{24}$ Em resumo, no pensamento do autor, a "confederação de Estados possui muito bem personalidade internacional. Mas seus membros a possuem, muito bem entendido, pela própria razão de seu caráter de Estados". ${ }^{25}$ Reconhece que tantos os Estados confederados, como o poder central, dispõe do direito de guerra ${ }^{26}$; do direito de legação ${ }^{27}$; e do direito de concluir tratados, mais amplo até do que o dos Estados confederados. ${ }^{28}$

A fim de contextualizar a formulação de Le Fur em sua obra État Fédéral et Confédération d'États, deve-se recordar que o período histórico, anterior à Primeira Guerra Mundial e à criação da Sociedade das Nações, ainda não oferecia ao autor uma realidade compatível com o desenvolvimento das organizações internacionais. Le Fur trabalhava um contexto em que, nessa qualidade, eram dignas de nota a União Telegráfica Internacional e a União Postal Internacional, fundadas em 1865 e 1874,

\footnotetext{
${ }^{20}$ Id., p. 499 (tradução nossa).

${ }^{21}$ Id., p. 501.

${ }^{22}$ Id., ibid.

${ }^{23}$ Id., p. 746 (tradução nossa); v. tb. p. 411-412.

${ }^{24}$ Id., ibid. (tradução nossa).

${ }^{25}$ Id., p. 748 (tradução nossa).

${ }^{26}$ Id., p. 752.

${ }^{27}$ Id., p. 755.

${ }^{28}$ Id., p. 757.
} 
respectivamente. A obra foi escrita antes mesmo da Primeira Conferência de Paz da Haia, ocorrida em 1899. Por isso, interessa-nos voltar ao tema dos Estados e das confederações dos Estados na análise feita pelo autor em 1933, na obra Précis de Droit International Public, na qual Le Fur já leva em consideração a evolução do contexto histórico ocorrida desde 1896, ano de publicação de État Fédéral et Confédération d'États - e também retoma a análise sobre os sujeitos do Direito Internacional, de forma mais sofisticada.

\section{ANÁlise dA OBRA PRÉCIS DE DROIT INTERNATIONAL PUBLIC, SOB A Ótica de SUA RELAÇÃO COM A OBRA ANTERIOR DO MESMO AUTOR E, FINALMENTE, NO TOCANTE AO FUNDAMENTO DO DIREITO INTERNACIONAL}

A análise da obra Précis de Droit International Public dar-se-á aqui em três planos: primeiramente, no tocante à análise do Estado federal e das confederações de Estados, de forma a permitir comparações com a primeira obra acima analisada (2.1); em segundo lugar, com relação à análise dos sujeitos de Direito Internacional que não os Estados, em particular no tocante à Sociedade das Nações (2.2); em terceiro lugar, no que diz respeito à norma de Direito Internacional, com especial consideração à argumentação de Le Fur sobre o fundamento do Direito Internacional, e às relações que podem ser traçadas com outros pensadores que contribuíram para o estabelecimento do pensamento internacionalista clássico (2.3).

Antes de passarmos à análise propriamente dita, cumpre dizer duas palavras sobre o contexto em que o autor se vê se inserido, face aos desdobramentos que o separavam, já, da primeira obra. O próprio autor retrata tais desdobramentos em seu entendimento peculiar. Primeiramente, afirma Le Fur que o Direito Internacional havia evoluído mais nos dez anos anteriores, ao tempo em que escrevia, do que nos dez séculos antecedentes ${ }^{29}$; segundo, acredita ele ainda que a Primeira Guerra Mundial e os desastres dela decorrentes marcaram o início de uma tentativa de reconstrução do

${ }^{29}$ LE FUR, Louis. Précis de Droit International Public. Paris : Dalloz, 1933, p. 1. 
Direito Internacional ${ }^{30}$; e finalmente, enxerga como o grande problema do Direito Internacional, à época, o papel da Sociedade das Nações e a conciliação de sua competência com a soberania dos Estados, comparando esse problema com o da conciliação da soberania estatal com os direitos individuais, no plano interno. ${ }^{31}$

\section{Considerações do autor sobre o Estado federal e as confederações de Estados, face à evolução do contexto histórico de 1896 a 1933}

Em Précis de Droit International Public, Le Fur define o Estado como "a sociedade representada pelos poderes públicos para tudo quanto se constitui em questão de direito" ${ }^{32} \mathrm{O}$ fato de que o Estado necessita de um território fixo por si só exclui dessa noção "as tribos nômades que se encontram num estado de organização menos evoluído".33

A soberania, ou autoridade comum, consiste no "direito do Estado de decidir em último recurso sobre as questões de sua competência, ao lado do monopólio sobre a coerção incondicionada". ${ }^{34}$ Outros sujeitos, como o chefe de família, o sindicato, a comuna, a província e a colônia podem gozar do direito de coerção, porém será esta condicionada. ${ }^{35}$ A soberania não é o direito de tudo fazer; os homens que a exercem podem fazê-lo mal, porém, segundo o direito objetivo ou racional, estão eles ligados entre si e aos outros homens "pelas regras morais e jurídicas que se impõem a todos, e assim o são também do ponto de vista político e econômico por meio da noção de fim a perseguir (o bem comum do grupo)". ${ }^{36}$

No plano externo, a soberania não é senão menos limitada. Ela se dirige ao atendimento das necessidades das relações entre os Estados, e também ao bem comum de um grupamento do qual todos os Estados fazem parte: a comunidade internacional ou sociedade de Estados. ${ }^{37}$ Porém, para que o Estado seja completo e verdadeiro, é

\footnotetext{
$3^{30}$ Id., p. 57, § 123.

${ }^{31}$ Id., p. 139, § 305 .

32 Id., p. 62, § 131 (tradução nossa).

33 Id., ibid., § 132 (tradução nossa).

34 Id., p. 63, § 133 (tradução nossa).

35 Id., ibid., § 134, nota de rodapé 2.

${ }^{36}$ Id., ibid. (tradução nossa).

37Id., ibid., § 135.
} 
necessário que goze de completa independência em relação a outros Estados $^{38}$; é sua tarefa zelar pela manutenção da ordem e da justiça no interior e de sua independência no exterior ${ }^{39}$.

Conforme exposto, Le Fur trabalha agora um contexto histórico diferente daquele experimentado por ocasião da obra anterior. Portanto, o autor já se preocupa em analisar a adesão dos Estados à Sociedade das Nações, criada em 1919. ${ }^{40}$ Nesse sentido, afirma Le Fur que a adesão dos Estados à Sociedade das Nações nada tem de incompatível com sua soberania, uma vez que dela se tornam partes em virtude de sua própria vontade e são livres para dela sair quando assim entenderem..$^{41}$ Essencial, na verdade, é não existir laço de dependência jurídica em relação a outro Estado; pois todos os Estados são, até certo ponto, dependentes da comunidade internacional, que representa os interesses gerais da Humanidade..$^{2}$

Passa então Le Fur a trabalhar as diversas categorias de Estados. Uma distinção fundamental é aquela entre o Estado unitário e o Estado composto. Por outro lado, há os Estados completos, ou soberanos, e aqueles ditos semi-soberanos, como o Estado vassalo ou protegido. No Estado composto, as relações entre os Estados membros da união é estabelecida em bases de igualdade; já no caso dos Estados protetores e protegidos, a relação é de subordinação. ${ }^{43}$ Mas, no Estado unitário, apesar de haver uma única soberania, um único centro de impulsão política e governamental, situado na metrópole, este pode conviver com colônias submetidas a um regime especial. ${ }^{44}$

Essa abordagem de Le Fur, justificando a manutenção de colônias por um Estado soberano, em particular um Estado unitário (como é o caso da França), está em linha com o contexto histórico vivenciado pelo autor - aquele do neocolonialismo - e é compatível com uma visão nacionalista do ponto de vista francês. Com efeito, em 1933 a França mantinha, além de suas possessões no Caribe e na América do Sul (Guiana

\footnotetext{
$3^{8}$ Id., p. 65 , § 141.

${ }^{39}$ Id., p. 64, § 136.

${ }^{40}$ Cabe recordar que a Liga (ou Sociedade) das Nações foi criada pela Parte I, Artigos 1 a 26, do Tratado de Versalhes, o qual entrou em vigor em 10 de janeiro de 1920.

${ }^{41}$ Id., p. 66, § 143 .

${ }^{42}$ Id., p. $67, \S 144$.

43 Id., ibid., § 146-147.

${ }^{44}$ Id., p. 68 , § 150.
} 
Francesa), a soberania, o protetorado ou a tutela sobre o Marrocos, parte da Argélia, a Tunísia, o Benin, Camarões, o Congo, parte da Guiné, Mali, Mauritânia, Níger, Senegal, Togo e Djubuti, dentre outros, na África; a Síria, o Líbano e o Sul do Iêmen, no Oriente Médio; Comores e Madagascar, no Oceano Índico; na Ásia, a Indochina, o Laos, o Camboja e o Vietnã, além de deter concessões sobre Xangai, Tianjin, parte de Wuhan e Guagzhou, na China; para não contar a Polinésia Francesa e outros territórios em que a presença francesa encontrava oposição da Grã-Bretanha, como por exemplo a Palestina e o Iraque.

Porém, Le Fur considera que as uniões de Estados realizadas por via de subordinação - como no caso dos Estados vassalos ou dos protetorados -são formas transitórias, uma vez que sempre realizadas à revelia da vontade do Estado subordinado, que tende a recobrar a sua independência - ainda que tenha de lutar por ela - ou cair definitivamente na categoria de província ou colônia. ${ }^{45}$ Do ponto de vista principiológico, acrescenta o autor, tal forma de união "aparenta ser pouco conforme ao princípio de direito internacional da igualdade jurídica entre os Estados". ${ }^{46}$ Não obstante, na prática, para ele, a forma do protetorado apresenta vantagens, sendo "melhor aceita pelos indígenas do que a anexação pura e simples ou a conquista", além de "muito mais prática e econômica do que a anexação". 47

Louis Le Fur revisita suas concepções a respeito do Estado federal e das confederações de Estados, expressadas na obra anteriormente analisada. $\mathrm{O}$ autor defende que as confederações de Estados já haviam, então, desaparecido ${ }^{48}$; porém, começa a enxergar uma nova acepção para o termo, como se pode depreender da seguinte passagem:

“Dans la Confédération d'États, il n’y a pás de véritable pouvoir public central, et notamment pas de pouvoir législatif. Il existe bien une sorte d'Assemblée de plénipotentiaires, - un peu comme l'Assemblée de la Société des Nations aujourd'hui -,

45Id., ibid., p. 97, § 216.

${ }^{46}$ Id., ibid., § 217 (tradução nossa).

47 Id., p. 102, § 227 (tradução nossa).

${ }^{48}$ Id., p. 73, § 163. 
mais puisque les Etats restent souverains, cette Assemblée ne peut en principe prendre de décisions qu'à l'unanimité, toujours comme dans la Société des Nations".49

Como se pode perceber, Le Fur volta atrás em sua concepção anterior a respeito da existência de um poder central nas confederações de Estados, dizendo agora que esse poder, se existe, não é "verdadeiro". Aprofunda sua revisão conceitual comparando a Sociedade das Nações - confederação de Estados lato sensu ${ }^{50}$ ou futura ${ }^{51}$ - com as confederações de Estados clássicas. E reconhece que, nas confederações de Estados, embora haja algumas decisões que possam ser tomadas por maioria, a unanimidade é exigida por princípio, "para que os Estados permaneçam soberanos" 52 . Essa seria, na visão de Le Fur, a causa de falência das confederações de Estados, que estariam fadadas à anarquia ou à dissolução, sendo que um golpe de força da maioria seria o único recurso contra essa derrocada53.

Além disso, o fato de que decisões da Dieta de uma confederação de Estados serem executadas, não por um poder executivo pertencente à própria confederação, mas pelos próprio Estados membros - o que faz com eles as executem apenas quando isso lhes interessa - é uma "nova e grande causa de falência, que encontraremos novamente na Sociedade das Nações". ${ }^{4}$ Para Le Fur, a confederação de Estados terá um de dois destinos: ou se dissolverá e os seus membros tomarão caminhos distintos; ou encontrará seu fim na transformação em Estado federal.55 Pode-se interpretar essa afirmação, na opinião dos autores, como também dizendo respeito à Sociedade das Nações - no tocante ao desmantelamento. Ainda segundo Le Fur, quando ocorre este último fenômeno - o da transformação em Estado federal -, os Estados membros deixam de ser soberanos, passando a "ser eleitores e participar, como tais, na formação da soberania nacional. Tal será também o caso da Sociedade das Nações, se um dia vier

\footnotetext{
49Id., ibid., § 164. "Na Confederação de Estados, não existe um verdadeiro poder público central, notadamente um poder legislativo. Existe, sim, uma espécie de Assembleia de plenipotenciários - um pouco como a Assembleia da Sociedade das Nações hoje em dia - mas uma vez que os Estados permanecem soberanos, essa Assembleia não pode, em princípio, tomar decisões a não ser por unanimidade, exatamente como na Sociedade das Nações" (tradução nossa).

$5^{50}$ Id., p. 141, § 310.

${ }^{51}$ Id., p. 144, § 313 .

52 Id., p. 74, § 164 (tradução nossa).

53 Id., ibid., § 165.

54 Id., ibid. (tradução nossa).

55 Id., ibid., § 166.
} 
a se transformar em verdadeiro Estado Federal, em lugar da simples confederação de Estados que ela permanecerá sendo, sem dúvida, por muito tempo" ${ }^{56}$

Le Fur, portanto, é pessimista com relação à possibilidade da transformação da Sociedade das Nações em Estado supranacional, o que fica ainda mais claro no seguinte excerto, que trata do monopólio da coerção incondicionada pelo Estado:

"Il est encore ainsi aujourd'hui malgré la création de la Société des Nations, qui ne peut recourir à la contrainte que par l'intermédiaire des Etats, et il en sera ainsi jusqu'au jour, qui n’a arrivera sans doute jamais, où la Société des Nations constituera un super-Etat au sens propre du mot, désormais seul investi de la souvaraineté, c'est-àdire en réalité un Etat unique, universel". ${ }^{57}$

É sabido que a transformação em Estado federal não só não ocorreu com a Sociedade das Nações, como esta efetivamente se dissolveu, no contexto histórico da Segunda Guerra Mundial, tendo transferido todos os seus ativos para a Organização das Nações Unidas no dia 18 de abril de 1946. Não era ali que sonho do Super-Estado, idealizado por Abbé de Saint-Pierre em seu projeto de paz perpétua - aquele que, na opinião de Le Fur, "mais se aproxima do Pacto da Sociedade das Nações"58 - se concretizaria. E por falar em "sonho", é isso mesmo que Le Fur pensa a respeito da Sociedade das Nações como "esboço da humanidade unificada" 59 . Talvez, ele se interessasse em saber que as perspectivas para a ideia kantiana de uma "federação de Estados livres"6o, sob a égide da Organização das Nações Unidas, assim como, ainda mais intensamente, da União Europeia, melhorariam consideravelmente depois de 1945, embora não satisfazendo, até o presente momento, plenamente os planos e pretensões do pensamento iluminista.

\footnotetext{
${ }^{56}$ Id., p. 90, § 201 (tradução nossa).

57 Id., p. 92, § 205. "Continua sendo assim hoje em dia, malgrado a criação da Sociedade das Nações, que não pode recorrer à coerção a não ser por intermédio dos Estados, e continuará sendo assim até o dia, que não chegará certamente jamais, em que a Sociedade das Nações constituirá um SuperEstado no sentido próprio da palavra, o único investido de soberania - é dizer, em realidade, um Estado único, universal" (tradução nossa).

${ }^{8}$ Id., p. 137, § 301 (tradução nossa).

59Id., p. 141, § 309.

60 “Das Völkerrecht soll auf einen Föderalism freier Staaten gregründet seyn”. KANT, Immanuel. Zum ewigen frieden: Ein philosophischer Entwurf. Königsberg: Friedriech Nicolovius, 1795. Disponível em: http://philosophiebuch.de/ewfried.htm.
} 


\section{Considerações a respeito dos sujeitos de Direito Internacional, em especial com relação à Sociedade das Nações}

Le Fur inaugura sua análise a respeito dos sujeitos de Direito Internacional com o indivíduo; porém, coloca-o, não como sujeito direto, mas "último e indireto" do Direito Internacional: pois os Estados existem em função dos indivíduos, o que não deixa de ser verdadeiro quando se considera o plano de suas relações internacionais ${ }^{61}$. Não obstante, enumera situações em que o indivíduo é, por si próprio, sujeito direto do Direito Internacional, relacionando-se diretamente com o Estado, no plano internacional: extradição; casos de pirataria; o caso dos apátridas; cortes internacionais humanitárias, etc., embora tais casos permaneçam excepcionais, pois em regra o indivíduo aparece como "mascarado, por assim dizer, pelo Estado". ${ }^{62}$

Le Fur passará então à análise dos sujeitos de Direito Internacional que não os Estados soberanos. "É o caso de certas grandes coletividades que não são Estados, muito menos Estados soberanos, mas que possuem contudo uma personalidade internacional mais ou menos completa", como a Liga Hanseática, por exemplo. ${ }^{63}$ Os Estados membros dos Estados federais, por sua vez, possuem uma "certa” personalidade internacional, assim também alguns Estados protegidos. ${ }^{64}$ Mas é nas "comissões internacionais" que Le Fur concentrará sua análise, exemplificando, em primeiro lugar, com a Comissão Europeia do Danúbio.

Quanto aos escritórios internacionais sem personalidade jurídica, depois de 1919, é como se todos tivessem sido incorporados à Sociedade das Nações - caso que ele acredita ser o da União Postal Internacional. ${ }^{65}$ Esta visão poderia ser considerada um tanto quanto radical ou exótica hoje em dia, já que se considera perfeitamente aceitável a convivência da Organização das Nações Unidas não só com suas próprias comissões, que não são dotadas de personalidade autônoma, mas com outras organizações internacionais propriamente ditas, façam estas parte de seu sistema, ou não - como

\footnotetext{
${ }^{61}$ Précis, op. cit., p. 114, § 256.

62 Id., p. 116-117, § 258 (tradução nossa).

63 Id., ibid., § 259 (tradução nossa).

64 Id., ibid., § 260.

${ }^{65}$ Id., p. 118, § 265.
} 
ocorre com a Organização Mundial do Comércio e a Organização Internacional para a Migração, sem contar aquelas dedicadas à integração regional, além de outras, inclusive as não-governamentais.

Le Fur se propõe a analisar também a questão das raças: o quão relevantes seriam estas para o Direito Internacional? Suas conclusões são: que a raça não constitui um conceito jurídico e que a única instância na qual pode ser relevante para o Direito Internacional é aquela em que uma raça diferente da dominante, num certo Estado, reivindica o caráter de nacionalidade ou de minoria. ${ }^{66}$ Além disso, é apenas para proteger minorias - núcleos caracterizados pela raça, língua ou religião e que compartilham um "querer-viver coletivo" - que o Direito Internacional moderno autoriza a exceção ao princípio da não-intervenção. ${ }^{67}$ Mas nem as raças, nem as nações ou minorias constituem sujeitos do Direito Internacional: fora os Estados e algumas outras coletividades (como nos casos já citados dos Estados membros e dos Estados protegidos), Le Fur vê apenas dois sujeitos importantes dotados de personalidade jurídica internacional: a Santa-Sé e a Sociedade das Nações. ${ }^{68}$

Ambas, por sinal, são comparadas entre si por Le Fur, que considera o período anterior ao Tratado de Latrão (1929), ou seja, enquanto a Santa-Sé não possuía território. Esclarece então Le Fur que enxerga a Sociedade das Nações como dotada de direitos típicos da soberania, aproveitando para redefinir esta última como "uma noção sobretudo imaterial" (como é o caso da soberania espiritual do Vaticano), que "pode existir sem um território determinado", consistindo "essencialmente num direito de comando tendo em vista do bem comum do grupo". ${ }^{69}$ Mesmo assim, não passa a Sociedade das Nações de uma "espécie de aliança sindical em vista de um objetivo limitado, a manutenção da paz entre os povos" - uma pessoa internacional sui generis, com uma espécie de soberania, mesmo não possuindo território próprio, que poderá no futuro tornar-se uma confederação de Estados com um poder central, por enquanto fracamente constituído. ${ }^{70}$

\footnotetext{
${ }^{66}$ Id., p. 119, § 266.

${ }^{67}$ Id., p. 120, § 268.

${ }^{68}$ Id., p. 121, § 268.

${ }^{69}$ Id., p. 136, § 300 e nota de rodapé 2 (tradução nossa).

${ }^{70}$ Id., p. 143-144, §313.
} 


\section{A construção de Le Fur dizendo respeito ao fundamento do Direito Internacional}

Após explorar os temas básicos descritos acima, Le Fur passa a elaborar a respeito do Direito Internacional em sentido teórico. Nesse sentido, desenvolve importante raciocínio na busca de esclarecer os fundamentos do Direito Internacional. Para Le Fur, ao Direito Internacional não se pode negar o caráter de Direito: poucos foram os juristas que assim procederam, mas entre os filósofos, alguns se aventuraram a fazê-lo..$^{11}$ Kant, por exemplo, não vê ireito desconectado da sanção; contudo, objeta Le Fur, os Estados não estão para o Direito Internacional assim como os indivíduos estão para o direito interno. ${ }^{72}$ Ele talvez tivesse considerado curioso que um dos teóricos mais influentes do século vinte no campo das ideias jurídicas, Hans Kelsen, acompanharia Kant nesse particular, questionando o Direito Internacional em termos de delitos e sanções. Nas palavras de Kelsen:

"O Direito Internacional é Direito no mesmo sentido que o Direito nacional, contanto que, a princípio, seja possível interpretar como sanção ou como delito o emprego da força de um Estado dirigido contra outro".73

Le Fur reforça que o Direito Internacional não é mera "moral internacional", expressão utilizada no artigo 227 do Tratado de Versalhes. Refuta as ideias de Jhering e Jellinek, explicando que os Estados formam uma sociedade e estão sujeitos à interdependência, não podendo mais deixar de haver uma norma de Direito entre eles. ${ }^{74}$ Em sua formulação, o "Direito é a organização e a hierarquização dos interesses por meio da justiça"75, enquanto que o Direito Internacional é uma decorrência logicamente necessária de existência de uma sociedade de Estados, "frouxa, mas ainda assim uma

\footnotetext{
${ }^{71}$ Id., p. 16o, § 343 .

${ }^{72}$ Id., ibid.

73 KELSEN, Hans. Princípios do Direito Internacional. Tradução de Gilmar Antonio Bedin e Ulrich Dressel, revisão da tradução de Arno Dal Ri Júnior. Ijuí: Ed. Unijuí, 2010, p. 47.

74 Précis, op. cit., p. 161, § 344.

75 Id., p. 158-159, § 340 (tradução nossa).
} 
sociedade". ${ }^{6}$ Relaciona-se, neste pormenor, com Samuel Rachel, que entende que o Direito confere união às sociedades - as quais estão ligadas por um propósito comum.

Para ele, cumpre dividir o Direito Internacional entre positivo e racional (ou, ainda, objetivo, científico ou ideal). A expressão "direito natural" deve ser evitada pois, por equívoco dos autores do século dezoito, essa expressão foi associada ao estado de natureza, o que é um erro porque esse estado, na opinião de Le Fur, não passa de ficção, uma vez que o homem sempre viveu em sociedade; além disso, o direito natural era concebido como imutável, até mesmo nos detalhes de sua aplicação.77 Nesse sentido: “[...] on emploie l'expression de droit rationnel, pour indiquer qu'il est découvert par la raison s'exerçant sur le donné des faits sociaux, au premier rang desquels figure la nature même de l'homme". ${ }^{8}$ Neste sentido, Le Fur aproxima-se da concepção de Puffendorf, que deriva o direito natural da razão pura, negando o estado de natureza da forma como concebido por Hobbes, pois, para Puffendorf, a paz é o estado que deriva naturalmente da razão humana.

A transposição dessa ideia para o âmbito internacional justifica-se porque os Estados se compõem de indivíduos e, assim sendo, não se podem furtar a reconhecer as leis morais que aos indivíduos são impostas. Nesse sentido, o Direito Internacional é a prova de que é necessário "escolher" entre o Direito fundado na moral e aquele fundado na força. Se o Direito fosse simples coerção, não haveria Direito Internacional79, e a guerra, ou seja, o direito do mais forte, corresponderia ao estado de natureza entre as nações, como disse Kant. ${ }^{80}$ Essa a razão pela qual é errado vincular o Direito Internacional à vontade dos Estados. Muito menos se deve fundá-lo, como fazem Jhering e Jellinek, na teria da auto-limitação, pois "não se pode qualificar de direito uma norma que não se impõe a alguém a não ser que esse alguém queira". ${ }^{81} \mathrm{~A}$ soberania

\footnotetext{
${ }^{76}$ Id., p. 16o, § 342 (tradução nossa).

77 Id., p. 157, § 337.

${ }^{78}$ Id., ibid. "Emprega-se a designação de direito racional, a fim de indicar que ele é descoberto pela razão exercida sobre o dado dos fatos sociais, no ápice dos quais encontra-se a própria natureza humana" (tradução nossa).

${ }^{79}$ Nem mesmo no Pacto da Sociedade das Nações; id., p. 162, § 346.

${ }^{80}$ Id., p. 161, § 345 .

${ }^{81}$ Id., p. 163, § 349 (tradução nossa).
} 
absoluta é, portanto a negação do Direito Internacional ${ }^{82}$, que corresponde a uma renovação da ideia expressada em État Fédéral et Confédération d'États (v. acima).

Nem, por outro lado, repousa o fundamento do Direito Internacional no pacta sunt servanda, como querem os juspositivistas. Tal doutrina peca tanto por falta, quanto por excesso. Pois, é contraditório dizer que a soberania é ilimitada, e que os Estados estão obrigados a respeitar as convenções; sem contar que há obrigações que não decorrem de seu consentimento expresso, como as obrigações costumeiras. ${ }^{83}$ Ademais, o simples fato de que dois Estados concluíram um tratado não faz com que este seja considerado como obrigatório no âmbito do Direito Internacional: tal seria o caso de um tratado para o comércio de escravos ou para o favorecimento da pirataria, cujo cumprimento somente agravaria as violações ao Direito Internacional. ${ }^{84}$

Há até mesmo mais razões, no plano internacional, para rejeitar a vontade do Estado como fonte única do Direito, do que no plano nacional. Isso porque no Direito interno, as decisões da maioria submetem a minoria; porém, no Direito Internacional, a regra é a unanimidade; por isso, pode-se dizer, a julgar pelo pensamento dos positivistas, que onde não há acordo, não há direito, o que corresponde a uma verdadeira renúncia ao Direito Internacional. ${ }^{85}$

Le Fur conclui sua construção afirmando a necessidade de combinar os métodos histórico e dedutivo, orientando-se pela finalidade; pois não há lei sem finalidade, seja esta declarada ou não, e, para as sociedades e seres coletivos, tal finalidade é sempre o bem comum do grupo $^{86}$ - no caso da sociedade dos Estados, o bem comum da comunidade internacional, fundamento objetivo do Direito Internacional. ${ }^{87}$ Enfim, sintetiza:

“[...] le droit, aussi bien international qu’interne, ce n'est pas la volonté arbitraire de l'Etat, c'est-à-dire pratiquement des gouvernants, c'est une régle à fondement scientifique et non pas une question de majorité. C'est une régle, soit de justice, soit de

\footnotetext{
${ }^{82}$ Id., p. $162-163, \S 348$.

${ }_{83}$ Id., p. 172, § 366.

${ }^{84}$ Id., p. 171, § 365 .

${ }^{85}$ Id., p. 181-182, § 385.

${ }^{86}$ Id., p. 182, § 386.

${ }^{87}$ Id., p. 172, § 367 .
} 
science économique, que l'Etat peut méconnaitre comme il peut méconnaitre toutes les lois morales et économiques, mais qui n'en existe pas moins". ${ }^{88}$

\section{CONCLUSÃO}

Louis Le Fur nos leva a refletir sobre os limites do contratualismo e do voluntarismo como teorias justificadoras do Direito Internacional. Sua obra demonstra cabalmente a insuficiência dessas teorias para explicar a existência e o fundamento desse Direito. Ora, se os Estados estão apenas obrigados na medida em que com isso estiverem de acordo, então não existe Direito, e sim arbítrio; e o arbítrio não será capaz de levar a comunidade internacional à realização de sua finalidade - o bem comum -, já que obedecerá apenas a interesses e não a considerações morais. A dimensão econômica (o útil) é essencial à formação do Direito Internacional, mas na visão de Le Fur, deve não apenas ter caráter científico, como também se fundir com a dimensão moral (o bem), dando origem ao justo, que é o Direito.

Pode-se alegar que Le Fur faltou com um certo pragmatismo. Mas isso não só não é verdadeiro, pois ele jamais se distancia da consideração das condições reais de existência e funcionamento da comunidade internacional, como também contraditório, pois o que ele propõe é justamente firmar uma concepção idealista, não como verdade única e absoluta, mas como fundamento, teórico portanto, do Direito Internacional ele mesmo sugere a conciliação entre os métodos histórico e racional, reconhecendo que a inteligência, sozinha, não passa de uma capacidade, e que é necessário ocupá-la com as considerações advindas da observação.

Mesmo assim, para Le Fur, o Direito é a justiça operando na hierarquização de interesses, de forma que se presume aí uma justiça operante, que não se limita ao conhecimento das normas advindas dos processos racionais e científicos - quase que como por meio de uma revelação - mas quer também aplicá-las, mister para o qual dificilmente é possível crer ser possível prescindir da coerção. Le Fur, portanto, deve ser

\footnotetext{
${ }^{88}$ Id., p. 181, § 384. "O direito, seja internacional ou interno, não é a vontade arbitrária do Estado, quer dizer, dos governantes, mas uma norma de fundamento científico e não uma questão de maioria. Trata-se de norma, seja de justiça, seja de ciência econômica, a respeito da qual o Estado pode errar, como pode errar sobre todas as leis morais e econômicas, mas que nem por isso é menos existente" (tradução nossa).
} 
colocado entre aqueles pensadores que ajudaram a combater a ascensão do radicalismo positivista e voluntarista (dir-se-á: nacionalista), na esteira da ascensão histórica dos regimes totalitários do século vinte, mas certamente que suas respostas não são definitivas quanto à busca - incessante - pelo fundamento do Direito Internacional, busca essa que continua apesar dos esforços e da importante contribuição de pensadores do calibre de Louis Le Fur - e que desta contribuição muito se beneficia.

\title{
THE CONTRIBUTION OF LOUIS LE FUR TO THE INTERNATIONALISTC NEO-NATURAL LAW: FROM THE THEORETICAL ATTACK TO VOLUNTARISM UP TO THE GROUNDS OF INTERNATIONAL LAW
}

\begin{abstract}
The influence of Louis Le Fur is synthesized by the recapture of natural law thinking in the midst of a positivist context of ideas and legal theories. Le Fur analyzes the international life of States, lecturing on the sovereignty, its grounds and limits; studies the confederations of States and critically analyzes the League of Nations in the light of the Enlightenment project of perpetual peace; Finally, rests the foundation of international law in the rational or objective law, a limitation to the will of States, guided by the notion of purpose - the common good of the international community -, based on the consideration of moral reasons (the good) and economic (useful), which will result in a legal synthesis (the fair).
\end{abstract}

Keywords: Neo-natural law. Nations Society. State Confederation.

\section{BIBLIOGRAFIA}

ARÉCHAGA, E.J. ; VIGNALI, H.A. ; RIPOLL, R.P. Derecho Internacional Publico: Principios, normas y estructuras. Montevideo: Fundación de Cultura Universitaria, 2005.

DUPUIS, Charles. Les Antécédents de la Société des Nations. In : Recueils des Cours de l'Académie de Droit International de la Haye, Vol. 6o, 1937. 
KANT, Immanuel. Zum ewigen frieden: Ein philosophischer Entwurf. Königsberg: Friedriech Nicolovius, 1795. Disponível em: http://philosophiebuch.de/ewfried.htm.

KELSEN, Hans. Princípios do Direito Internacional. Tradução de Gilmar Antonio Bedin e Ulrich Dressel, revisão da tradução de Arno Dal Ri Júnior. Ijuí: Ed. Unijuí, 2010.

LE FUR, Louis. État fédéral et confédération d'États. Paris : Librairie Générale de Jurisprudence, 1896.

Vol. 58, 1936.

Règles Générales du Droit de la Paix. Recueil des Cours de l'Académie de La Haye,

Précis de Droit International Public. 2ª ed. Paris : Dalloz, 1933.

NOUR, Soraya. À Paz Perpétua de Kant : filosofia do Direito Internacional e das Relações Internacionais. São Paulo: Martins Fontes, 2004.

PUFENDORF, Samuel von. Do direito Natural e das Gentes. Prefácio de Tércio Sampaio Ferraz Junior. São Paulo: Imprensa Oficial, 2003.

RACHEL, Samuel. Dissertações sobre o Direito Natural e das Gentes. 1676.

Trabalho enviado em 24 de novembro de 2014.

Aceito em 22 de janeiro de 2015. 